\title{
XI. On the existence of a real or imaginary root to any equation
}

\section{R. Murphy Esq. M.A.}

To cite this article: R. Murphy Esq. M.A. (1833) XI. On the existence of a real or imaginary root to any equation, Philosophical Magazine Series 3, 2:7, 60-61, DOI: $10.1080 / 14786443308647964$

To link to this article: http://dx.doi.org/10.1080/14786443308647964

册 Published online: 01 Jun 2009.

Submit your article to this journal $[\pi$

Џ Article views: 2

Q View related articles $\asymp$ 
of the same piece when the flame was fed with cold air; but $I$ did not succeed in melting it. A piece of platinum foil, however, showed signs of fusion upon its edges. By heating the current of air to a still higher degree, by exposing it in its course to a larger and a hotter surface, I should not despair of accomplishing this object.

Indeed, since I have had the good fortune to show that the highest temperature of our furnaces does not, probably, exceed $3500^{\circ}$ Fahrenheit, instead of $22,000^{\circ}$, al which it has been, till yery recently, estimated *, it is easy to understand how a supply of air at $600^{\circ}$ or $700^{\circ}$ may increase their efficiency; and that a like augmentation of temperature bears a considerable proportion to the melting point of cast iron reckoned at $2800^{\circ}$, which would be perfectly insignificant if the same point were $18,000^{\circ}$.

I remain, my dear Sir, yours very truly,

King's College, Dec. 6th, 1832.

J. F. Daniell.

XI. On the Existence of a Real or Imaginary Root to any Equation. By R. Murphy, Esq. M.A. Fellow of Caius College, Cambridge + .

LT $f(x)=0$ be any given equation : put $x=p+q \sqrt{ }$ T. Then giving to $p$ and $q$ all possible values, there must be, amongst the values of $f(x)$ which result, some one exactly $=0$.

For if not, if we reject all the imaginary results, there must be some one amongst the real ones nearer to zero than any other; let the values of $p$ and $q$ be then $\mathrm{P}$ and $\mathrm{Q}$, and let $R$ be the value of the function.

Let $h$ be an indefinitely small quantity, then changing $\mathbf{P}$ into $\mathrm{P}+h, \mathrm{R}$ would be changed into $\mathrm{R}+\mathrm{A} h^{n}$ (retaining only the lowest power of $h$ ).

But if we change simultaneously $\mathrm{P}$ into $\mathrm{P}+h \cos \frac{\pi}{n}$, and $\mathbf{Q}$ into $\mathbf{Q}+h, \sin \frac{\pi}{n}$, the whole increment to $n$ or $\mathbf{P}+\mathbf{Q} \sqrt{-1}$ is then $h\left(\cos \frac{\pi}{n}+\sqrt{-1} \sin \frac{\pi}{n}\right)$; and consequently $f(x)$ or $\mathbf{R}$ would become $\mathbf{R}+\mathbf{A} h^{n}\left(\cos \frac{\pi}{n}+\sqrt{-1} \sin \frac{\pi}{n}\right)^{n}$ $=\mathrm{R}-\mathrm{A} h^{n}$.

* See Prof. Daniell's papers on his new Register Pyrometer, in Phil. Mag. and Annals, vol, xi.; and Phil. Mag. and Journ. of Science, vol. i._-ED1T.

$\uparrow$ Communicated by the Author. 
If, therefore, the change first effected does not give a result nearer to zero than $\mathbf{R}$, the second one will, and vice vers $\hat{a}$; contrary to hypothesis.

Hence the proposition must be true.

Cambridge, Dec. 20, 1832.

XII. Notice respecting the Determination of the Geographical Positions of the Village of Chamouni, and the Convent of the Grand St. Bernard. By J. D. Forbes, Esq. F.R.S. L. \& E.*

A MONG the instruments with which I provided myself before leaving Britain, was a portable altitude and azimuth circle, constructed for me upon Captain Kater's principle, by Mr. Robinson, precisely similar to that which accompanied Captain Parry upon his last journey towards the Pole. It is considerably larger than the instruments usually made by Mr. Robinson of this form, and proportionably more perfect. The circles have a diameter of $4 \frac{\mathrm{T}}{2}$ inches, and are divided to $15^{\prime \prime}$. The azimuth circle has three verniers; that for altitude, two. Two telescopes accompany the instrument, with three simple eye-pieces, and a diagonal one. The level is an excellent one, and there are various other appendages which I shall not at present particularize.

I intended to use this circle rather as a theodolite than an astronomical instrument; but my friend Professor Gautier, of Geneva, to whose kindness I have been much indebted during my stay in that place, suggested that I should make it the companion of my journey in Savoy, and determine the position of two points of interest, (for neither of which have we any direct observations,) Chamouni, and the Convent of the Grand St. Bernard; the last in particular is interesting, from the importance which attaches to it as a meteorological station. I readily adopted his suggestion; and had reason to be satisfied with the capability of the instrument to resist shocks, having been carried during the greater part of the journey upon a mule. The weather at Chamouni was far from favourable, and I only obtained two series of simple altitudes of the sun on different days, for the time, and three altitudes of Polaris at intervals during a cloudy evening. At St. Bernard I was more fortunate; I obtained corresponding altitudes on the evening of the 30th of Angust, and the succeeding morning, which gave the time of apparent midnight: and I took eight successive altitudes of Polaris, half with the face of

* Read before the Royal Society of Edinburgh, December 3, 1832 ; and communicated by the Author. 